\section{Improving survival in children with AIDS in Brazil: results of the second national study, 1999-2002}

\author{
Ampliação da sobrevida em crianças com AIDS no \\ Brasil: resultados do segundo estudo nacional \\ de 1999 a 2002
}

\author{
Luiza Harunari Matida ${ }^{1}$ \\ Alberto Novaes Ramos Jr. ${ }^{2}$ \\ Jorg Heukelbach 2 \\ Adriana Sañudo 3 \\ Regina Célia de Menezes Succi 4 \\ Heloisa Helena de Sousa Marques 3 \\ Marinella Della Negra 5 \\ Norman Hearst 6
}

\section{Abstract}

1 Programa Estadual de DST/ AIDS, Secretaria de Estado da Saúde de São Paulo, São Paulo, Brasil.

2 Faculdade de Medicina

Universidade Federal do Ceará, Fortaleza, Brasil.

3 Faculdade de Medicina Universidade de São Paulo, São Paulo, Brasil.

4 Departamento de Pediatria Universidade Federal de São

Paulo, São Paulo, Brasil.

5 Faculdade de Ciências

Médicas da Santa Casa de

São Paulo, São Paulo, Brasil.

6 University of California,

San Francisco, USA.

Correspondence

L. H. Matida

Programa Estadual de DST/

AIDS, Secretaria de Estado da

Saúde de São Paulo.

Rua Santa Cruz 81, São

Paulo, SP 04221-000, Brasil.

lmatida@gmail.com
The objective of this study is to characterize survival in children with AIDS diagnosed in Brazil between 1999-2002, compared with the first national study (1983-1998). This national retrospective cohort study examined a representative sample of Brazilian children exposed to HIV from mother-to-child transmission and followed through 2007. The survival probability after 60 months was analyzed by sex, year of birth and death, clinical classification, use of antiretroviral therapy (ART) and prophylaxis for opportunistic diseases. 920 children were included. The survival probability increased: comparing cases diagnosed before 1988 with those diagnosed from 2001-2002 it increased by 3.5-fold (from $25 \%$ to $86.3 \%$ ). Use of ART, initial clinical classification, and final classification were significant $(p<0.001)$ predictors of survival. Issues regarding quality of records and care were identified. The results point to the success of the Brazilian policy of providing ART. The improvement of clinical status contributes to quality of life, while indicating challenges, particularly practices to improve long-term care.

Acquired Immunodeficiency Syndrome; Infections Disease Transmission; Survival Analysis; Highly Active Antiretroviral Therapy

\section{Introduction}

In the past 10 years especially, evidence has been accumulated regarding reduction of morbidity and mortality from HIV infection in both adults and children 1,2,3,4,5,6,7. Even with the emergence of chronic diseases associated with HIV and its treatment 8 , overall improvements have been clearly documented in both developing and developed countries. Brazil stands out for its sustained policies to combat the epidemic 8,9,10,11,12.

To assess the impact of these actions, the analysis of survival times in children with AIDS is crucial, with various implications for both individuals and public health 13 . In addition to assessing needs relating to patient care and the establishment of public policies, it represents a key outcome to assess interventions aimed at prolonging life 14 .

In Brazil, few studies have evaluated survival in children with AIDS 10. The first national study obtained some of the first evidence regarding the impact of drug access on survival in children infected by vertical transmission in developing countries 14,15 . Overall survival to 60 months was $52.8 \%$ (95\% confidence interval - 95\%CI: 41.960.8) in 914 AIDS cases reported from 1983 to 1998 and followed to the end of June 2002. In this study, over time there was a significant improvement in survival among Brazilian children with AIDS infected through vertical transmission, with 
over $75 \%$ of cases diagnosed in 1997 and 1998 still living five years after diagnosis 15 .

The lack of survival studies in the country, especially in the pediatric population, and changes in medical services and treatments since 1998 justified a new expanded national study of survival in pediatric AIDS patients. These changes require ongoing monitoring of survival time, as does the need to evaluate the impact of inequality in access to preventive and treatment measures.

Preliminary results of the second national study, which included children diagnosed with AIDS from 1999 to 2002, showed a continuation of the improving trend found in the first study, with a survival probability at 60 months of $86.3 \%$ (95\%CI: 84.1-88.5) 16. It also drew attention to issues like quality of health care, types of antiretroviral therapy and prophylaxis for opportunistic infections. This article aims to present a deeper analysis of survival in children with AIDS diagnosed between 1999 and 2002, exposed to HIV through vertical transmission and followed until 2007. We also place these results in the context of the first national study.

\section{Methodology}

\section{Study design}

This is the second multicenter retrospective cohort survival study of Brazilian children (0 to 12 years of age) with AIDS 16. It is characterized by being a historical cohort, following a similar methodology to the first national study (between 1983 and 1998). This earlier study has been described in detail previously 15 ; we note some highlights below.

\section{Study population}

A population-based study was composed of AIDS cases in children living in 26 states and the Federal District of Brazil. The Notifiable Diseases Information System (SINAN) specific for AIDS in children was taken as a reference database. This database of the Brazilian National STD/AIDS Program was accessed from the Brazilian Ministry of Health in February 2006 and included 3,826 AIDS cases in children diagnosed between 1999 and 2002.

The sample size was determined to allow significant comparisons between proportions of survivors at particular times. The study sample was probabilistic, stratified, and selected cases in two stages: municipalities and individual cases. It was divided into four regional strata: the North- east, Southeast, South, and a combination of the North and Midwest. Considering the low number of cases in this latter stratum there was no sampling, and all cases diagnosed during the study period were included.

Only municipalities with more than two cases reported were included; $38.9 \%$ of municipalities had only one reported case, while $52.6 \%$ had two reported cases. Excluding these, 145 remaining municipalities were responsible for the reporting of 3,629 cases, $94.7 \%$ of all cases in Brazil. The Northern Region had 120 cases in 7 counties; the Northeast Region, 363 cases in 16 counties; the Midwest Region, 190 cases in 6 counties; the Southeast region, 1,964 cases in 73 counties; and the Southern Region, 992 cases in 43 municipalities.

Parameters for the sample size calculation were based on the results of the first national survival study. We assumed median survival of approximately 8.5 years and a mortality coefficient of 0.0815 . Based on these criteria, we selected 1,444 children (under 13) with AIDS registered in SINAN during the period from 01 January 1999 to December 31, 2002. Follow up continued until death or the end of 2007.

\section{Data collection}

The process of data collection was continued until December 2007. It consisted of initial contact with health services where the case had been treated, records location and transcription of available information for an abstraction form, based on one used in the first national study. The local staff of the State Program for the Control of STD/AIDS and of care facilities was contacted to explain the study and to confirm the accuracy of data regarding medical history and current status. This included health care professionals directly or indirectly involved with patient care, surveillance and/or research related to HIV/AIDS in children.

Additional sources of information were the databases of the Mortality Information System (SIM-DATASUS), the Drugs Logistics Management System (SICLOM-MS) and the Laboratory Tests Control System (SISCEL-MS). To this end, we used the software Rec Link2.0 17, following the methodology adopted by the Ministry of Health and matching on the child's name, mother's name and date of birth 18 .

\section{Data analysis}

The study database was analyzed using the Statistical Package for Social Sciences (SPSS Inc., Chicago, USA) version 15.0. Besides descriptive 
analysis, the survival probability at 60 months was calculated, with the binomial 95\%CI. We then proceeded to the construction of survival curves using the Kaplan-Meier estimate of survival probability 19,20.

Survival analysis aimed at assessing the occurrence of AIDS-related death as an outcome within a period of time that had the date of the case definition of AIDS in children as the starting date. The date of AIDS diagnosis was reassessed during the search using the AIDS case definition used in Brazil since 200421.

Date of death was established through the evaluation of medical records and/or mortality system data, when available. For children whose information about death was not known, the date of censure was set as the date of the last recorded visit to health care services.

A sensitivity analysis showed that a weighted analysis adjusting for different sampling probability by location would change survival estimates by less than $1 \%$. We present the unweighted analysis for simplicity.

Comparisons of survival curves by sex, year of birth, year of diagnosis, classification (stage) of HIV infection (initial and current - for the sole purpose of comparison), use of prophylaxis for opportunistic diseases and antiretroviral therapy (used at any time) were performed using the logrank test or Breslow test 20,22.

\section{Ethical considerations}

The project was approved by the Research Ethics Committee at the Center for Reference and Training in STD/AIDS of São Paulo State, under protocol $n^{\circ} .090 / 2006$, following the guidelines of the National Health Council expressed in Resolution $n^{\circ} .196$ of 1996.

\section{Results}

In a first step, 462 (32\%) of the 1.444 cases identified were excluded for incorrect records in SINAN: duplication $(46=3.2 \%$ ), AIDS diagnosis outside the study period $(66=4.3 \%)$, cases of HIV infection but not AIDS ( $4=0.3 \%$ ) and cases of children exposed perinatally to HIV and uninfected (32 = $2.2 \%)$. We excluded another 291 (20.1\%) cases for which records could not be located during field work and 23 (1.6\%) with loss of follow-up and no significant information available. Of the remaining total of 982 children, 945 (97.5\%) were exposed to HIV through vertical transmission. The 37 remaining cases had the following forms of exposure to HIV: unknown/no information, 20 (2\%), transfusion of blood/components, 8 (0.9\%) indeterminate, $6(0.6 \%)$ and sexual, $3(0.3 \%)$. We eliminated an additional 25 cases for whom the date of death was the same as the date of diagnosis and who thus had zero follow-up time for analysis. Thus, a total of 920 cases were included in analysis.

The overall probability of survival for 60 months among these children diagnosed with AIDS in 1999 to 2002 was 0.883 (95\%CI: 0.8600.902). There were 109 deaths observed (11.9\%) and followed until the end of 2007; $78 \%$ of these deaths took place in the period of 1999 to 2002.

Figure 1 presents an integrated survival curve of the two national studies, according to different periods of AIDS diagnosis, showing the sustained gain in survival of these children.

In the first national study, considering the whole period from 1983 to 1998, the overall survival probability at 60 months was 0.528 (95\%CI: 0.419-0.608): before 1988, 0.197 (95\%CI: 0.1120.300 ); from 1988 to 1992, 0.273 (95\%CI: 0.229 0.319 ); from 1993 to $1994,0.397$ (95\%CI: 0.334 0.459 ); from 1995 to $1996,0.595$ (95\%CI: $0.528-$ 0.656); and from 1997 to 1998, 0,682 (95\%CI: 0.616-0.739). In this present study, the survival probability was 0.865 (95\%CI: $0.830-0.893)$ from 1999 to 2000 (470 children), and 0.902 (95\%CI: 0.870-0.927) from 2001 to 2002 (450 children).

Demographic, epidemiological and clinical characteristics of the 920 studied cases are presented in Table 1. There is a slight predominance of girls (51.7\%) as well as children born in the 1995-1998 cohort (47.3\%). In terms of year of AIDS diagnosis, there is a homogeneous distribution in the four years of study. Regarding initial clinical classification of HIV infection, $65.4 \%$ were classified as B (B1, B2 and B3) or C (C1, C2 or C3). In the final clinical classification, these two categories made up $40 \%$.

Of note is the frequency of missing data for some of these variables investigated in health services, such as: prophylaxis administration (23.1\%), current or final clinical classification (3.7\%), and initial clinical classification (1.9\%).

Figures 2 and 3 show the survival curves by initial and current/final clinical classification and survival curves by use of antiretroviral therapy (ART) and prophylaxis for opportunistic infections, respectively.

\section{Discussion}

This second national study of AIDS survival in children confirms the strengthening of positive trends observed in the first study 14 and shows the continuing increase in survival probability. The survival rate over the period improved sig- 


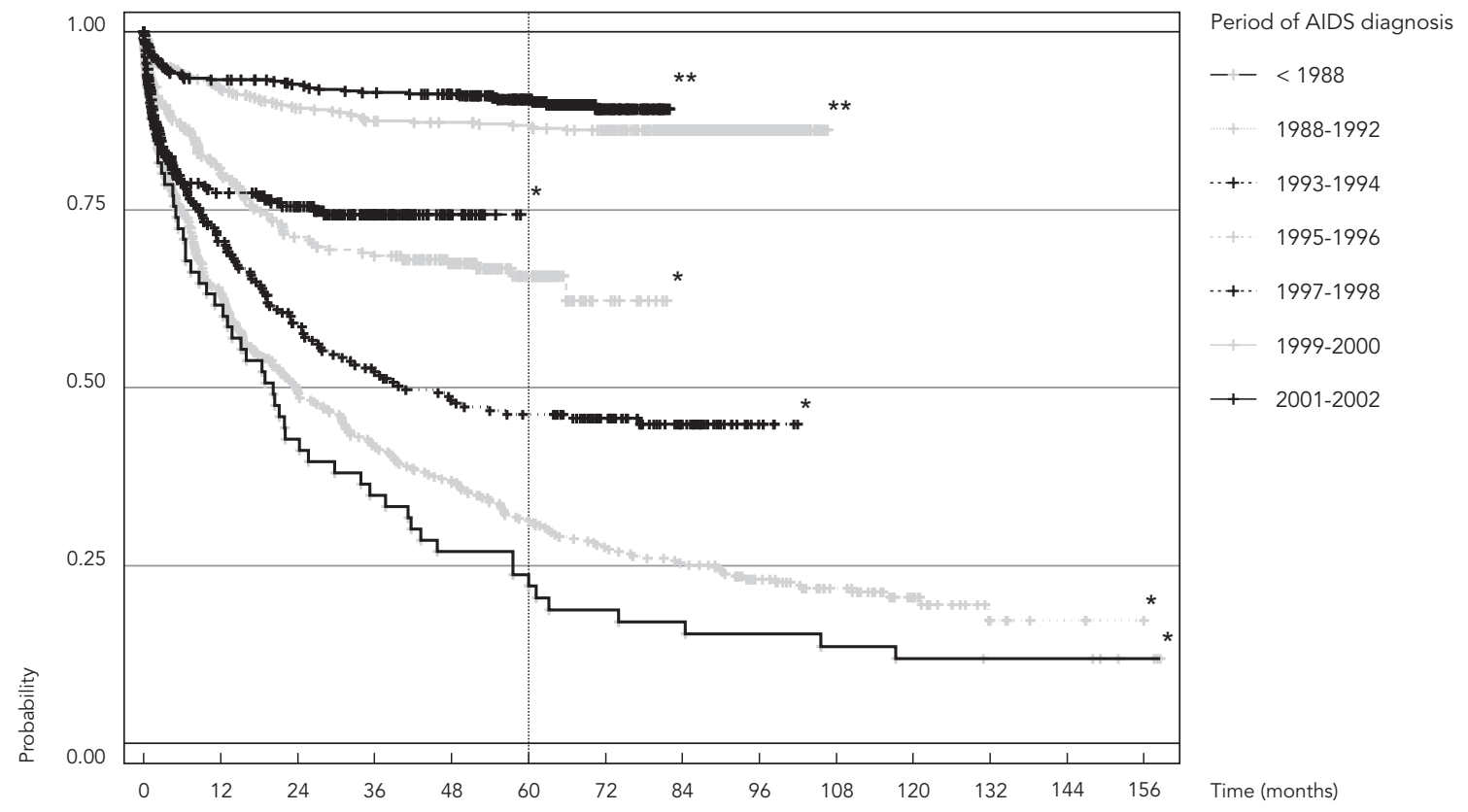

\footnotetext{
* 1st study

** 2nd study

Log-rank: $p<0.001$.
}

nificantly and consistently in Brazilian children with AIDS 16, a fact mirrored by other studies in different settings around the world 7,10,14,23,24,25.

The probability of survival at 60 months rose from $25 \%$ before 1988 to $88 \%$ in $2001-2002$, representing a 3.5-fold increase. Compared to the first national study, this study showed an overall improvement of about $36 \%$ in this probability.

These improved results were largely made possible by the development of a program of universal access to ART. In this study, $94.8 \%$ of children had received this treatment, with records of information of use or nonuse in $100 \%$ of cases. The survival probability at 60 months in children with recorded use of HAART (highly active antiretroviral therapy) was significantly ( $p<0.001)$ higher compared to those without.

In fact, the period from 1999 to 2002 represents a period of greater consistency in the use of HAART in the country, initially adopted in 1996. This is the result of the actions and health policies aimed at improving access and quality of HIV care 14 , a cost-effective initiative with significant impact on public health 26 . In this study, the vast majority of children $(85.1 \%)$ were born in a period of expanded ART availability. The higher survival rate observed in the cohort of children born in the period 1995-1998 (0.909; 95\%CI: 0.878-0.933) compared to $1999-2002$ (0.855; 95\%CI: $0.813-$ 0.889 ), was not statistically significant and may be associated with different ages of children at the time of diagnosis.

Moreover, greater access to early diagnosis and management of HIV infection and opportunistic diseases 10,11 might have contributed to the continuing increase in survival, similar to that observed in developed market economies 3,8 . In this study, no significant difference was found between having or not having used prophylaxis in the analysis of survival at 60 months. Only $76.9 \%$ of children had documentation about prophylaxis use for infections/opportunistic infections, pointing to the need for discussion about the importance of both the accuracy and the 
Demographic, epidemiologic and clinical characteristics, and survival probability at 60 months - 920 AIDS cases by vertical transmission. Brazil, $1999-2002$.

\begin{tabular}{|c|c|c|c|c|}
\hline Variables & $\mathrm{n}$ & $\%$ & $\begin{array}{l}\text { Survival probability at } \\
60 \text { months }(95 \% \mathrm{Cl})\end{array}$ & $p$-value \\
\hline Total & 920 & 100.0 & $0.883(0.860-0.902)$ & - \\
\hline \multicolumn{5}{|l|}{ Sex } \\
\hline Male & 444 & 48.3 & $0.877(0.842-0.905)$ & \\
\hline Female & 476 & 51.7 & $0.893(0.860-0.919)$ & 0.262 \\
\hline \multicolumn{5}{|l|}{ Year of birth } \\
\hline $1986-1990$ & 25 & 2.7 & $0.758(0.538-0.883)$ & \\
\hline $1991-1994$ & 112 & 12.2 & $0.892(0.817-0.937)$ & \\
\hline 1995-1998 & 435 & 47.3 & $0.909(0.878-0.933)$ & \\
\hline 1999-2002 & 348 & 37.8 & $0.855(0.813-0.889)$ & 0.426 \\
\hline \multicolumn{5}{|l|}{ Year of AIDS diagnosis } \\
\hline 1999 & 249 & 27.1 & $0.890(0.844-0.923)$ & \\
\hline 2000 & 221 & 24.0 & $0.836(0.780-0.879)$ & \\
\hline 2001 & 220 & 23.9 & $0.880(0.829-0.917)$ & \\
\hline 2002 & 230 & 25.0 & $0.924(0.880-0.952)$ & 0.216 \\
\hline \multicolumn{5}{|c|}{ Initial clinical classification } \\
\hline$N, N 1, N 2$ and N3 & 57 & 6.2 & $0.965(0.867-0.991)$ & \\
\hline $\mathrm{A}, \mathrm{A} 1, \mathrm{~A} 2$ and $\mathrm{A} 3$ & 244 & 26.5 & $0.983(0.954-0.994)$ & \\
\hline $\mathrm{B}, \mathrm{B} 1, \mathrm{~B} 2$ and $\mathrm{B} 3$ & 288 & 31.3 & $0.929(0.892-0.954)$ & \\
\hline$C, C 1, C 2$ and $C 3$ & 314 & 34.1 & 0.755 (0.703-0.799) & $<0.001$ \\
\hline Missing & 17 & 1.9 & - & \\
\hline \multicolumn{5}{|c|}{ Current/final clinical classification } \\
\hline$N, N 1, N 2$ and N3 & 193 & 21.0 & $0.995(0.964-0,999)$ & \\
\hline$A, A 1, A 2$ and $A 3$ & 325 & 35.3 & $0.994(0.976-0,999)$ & \\
\hline$B, B 1, B 2$ and $B 3$ & 188 & 20.4 & $0.947(0.903-0.971)$ & \\
\hline$C, C 1, C 2$ and $C 3$ & 180 & 19.6 & $0.504(0.427-0.575)$ & $<0.001$ \\
\hline Missing & 34 & 3.7 & - & \\
\hline \multicolumn{5}{|c|}{ Opportunistic infection prophylaxis } \\
\hline Yes & 658 & 71.5 & $0.885(0.857-0.907)$ & \\
\hline No & 50 & 5.4 & $0.785(0.635-0.897)$ & \\
\hline Missing & 212 & 23.1 & $0.900(0.850-0.933)$ & 0.438 \\
\hline \multicolumn{5}{|l|}{ Use of HAART } \\
\hline Yes & 872 & 94.8 & $0.904(0.882-0.922)$ & \\
\hline No & 48 & 5.2 & $0.492(0.343-0.624)$ & $<0.001$ \\
\hline
\end{tabular}

HAART: highly active antiretroviral therapy.

completeness of medical records. Given the high survival rate of children in this group, there was likely underreporting of this variable.

The implementation of the prevention of HIV transmission from mother to infant and early use of HAART are factors that delay the progression of the disease, demonstrated in the increase in average age of AIDS diagnosis 8 .

Despite the steadily increasing proportion of women with AIDS over the past ten years 27 and the likelihood of pregnancy in this population, the number of exposed children infected has been systematically reduced in Brazil 17,18,28,29. This re- duction reflects the implementation of actions to reduce vertical transmission of HIV throughout the country, despite different patterns of performance across regions due to operational, social and economic issues 10,30.

The measures adopted by various health services generated a pattern of improvement in clinical status of children. The results reinforce the relationship between clinical classification and probability of survival at 60 months, considering the initial classification and the current/ final classification, used here only for comparison. At first, $32.7 \%$ of children were classified as $\mathrm{N}$ 
Figure 2

Survival probability after AIDS diagnosis in 920 cases of vertical transmission by initial and current/final clinical classification, Brazil.

a) Initial clinical classification

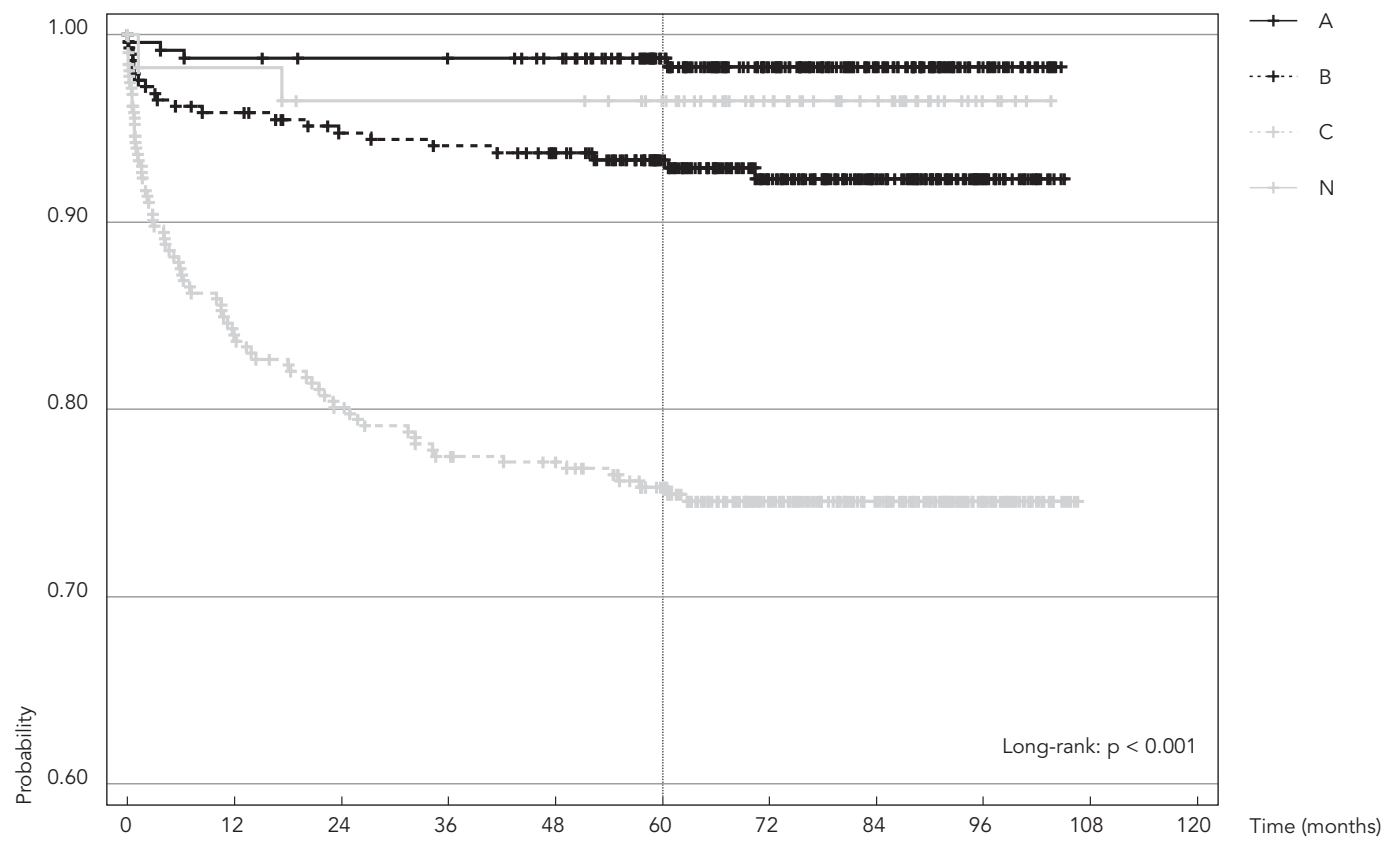

b) Current/final clinical classification

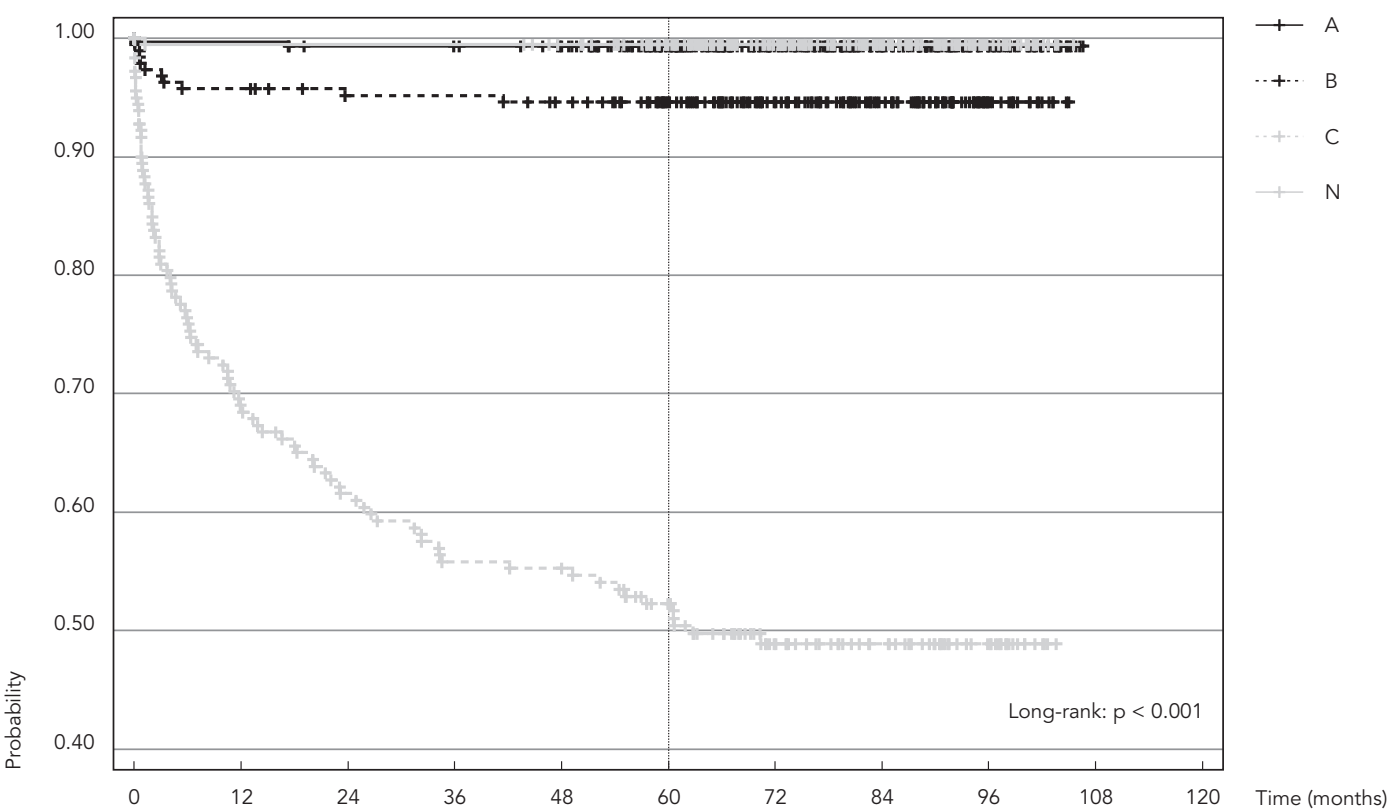


Figure 3

Survival probability after AIDS diagnosis in 920 cases of vertical transmission by use of antiretroviral therapy and prophylaxis for opportunistic infections, Brazil.

a) Antiretroviral therapy

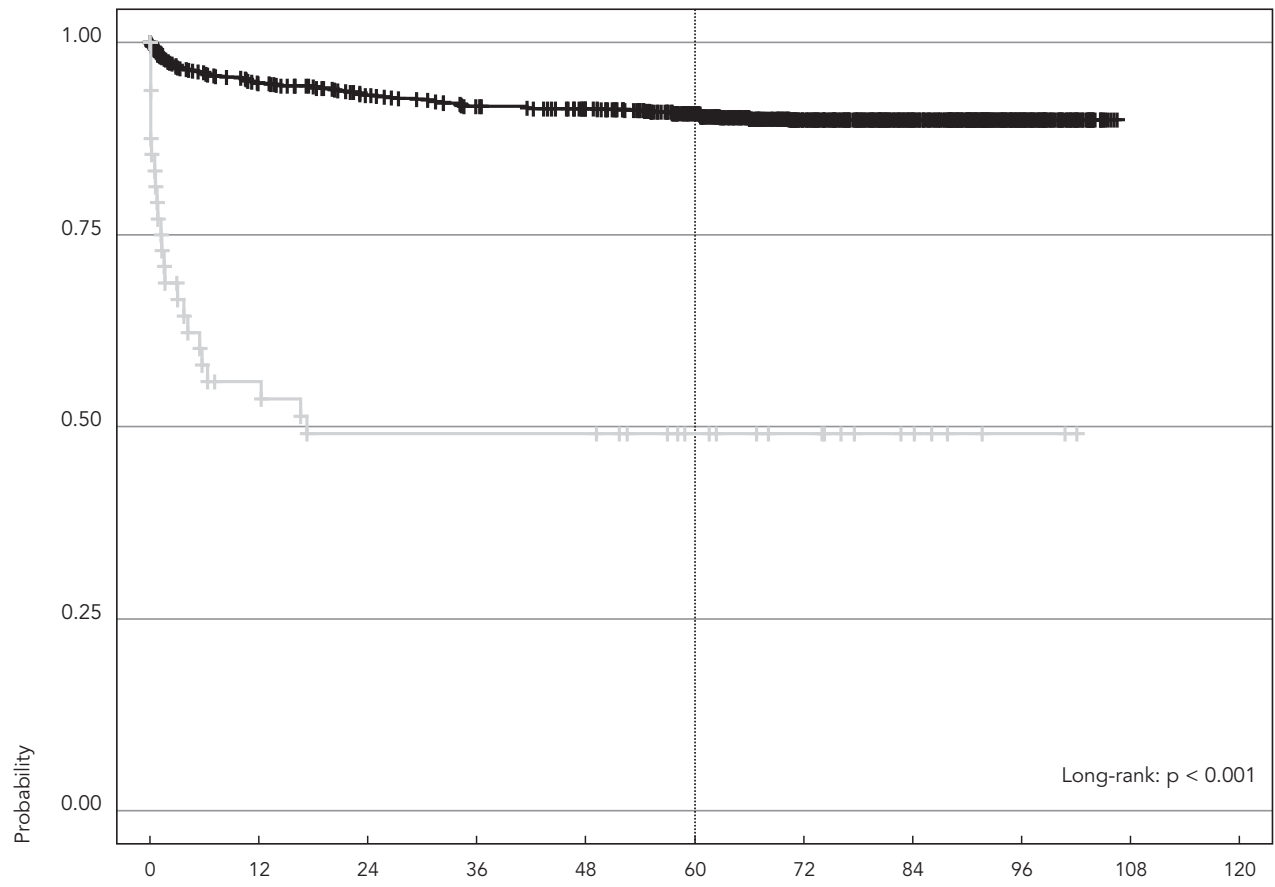

1 Antiretroviral therapy

No antiretroviral therapy

b) Prophylaxis

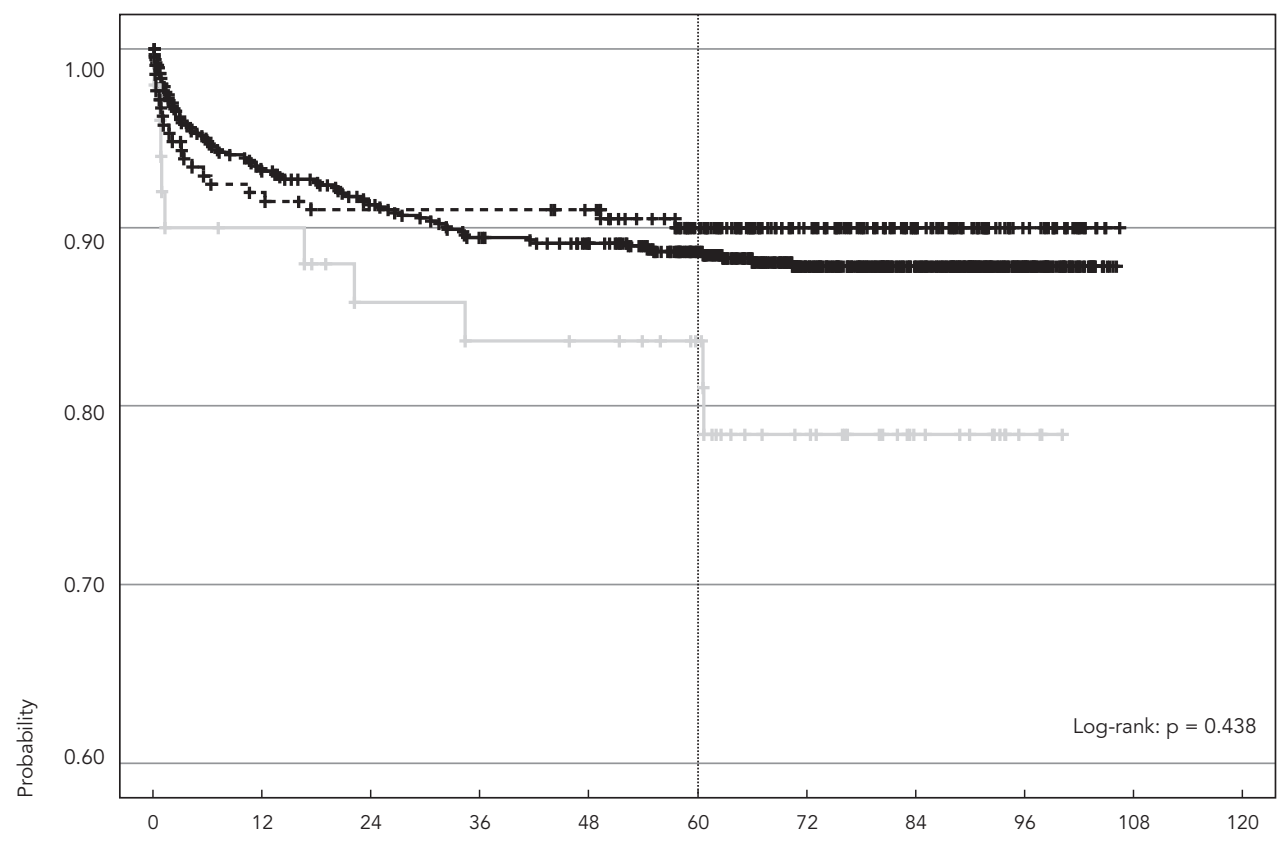

— Prophylaxis

$+\quad$ No prophylaxis

$\cdots+\cdots \quad$ Prophylaxis $=$ missing

Time (months) 
or A; by the current/final evaluation, $56.3 \%$ were documented to have this classification (Table 1), despite some missing information. In this study, we chose to consider the evolving pattern of classification only for comparative purposes.

Other variables were not identified as being significant in the survival probability at 60 months, such as sex, year of birth and year of AIDS diagnosis. Regarding gender, different studies reinforce these results. Regarding year of birth or AIDS diagnosis, the relatively short period studied and the lack of significant changes in management probably account for the lack of difference in terms of survival probability.

The results presented in this analysis (920 cases) are slightly different from those $(86.3 \%$, 95\%CI: 84.1-88.5) in a previously published preliminary analysis in which all cases (945 cases) had been included 16 . In the present analysis, the elimination of cases for whom the date of death was the same as the date of diagnosis and who thus had zero follow-up time for analysis improved the accuracy of the analysis.

Regarding limitations, one third of potential cases had to be excluded because of poor quality in the original database (SINAN) and in records in treatment services. These difficulties reinforce the need to document the care process and improve epidemiological surveillance. While these factors may have affected the estimate of survival, they would not explain the observed increase in survival, unless the magnitude of any bias had increased substantially over time. The finding of duplication and inconsistencies (children exposed to HIV but listed as uninfected, and those infected but listed as being without AIDS, for example) in the SINAN database reinforce this need. Despite these areas of improvement, the use of this database has the advantage of being representative of the Brazilian population.

Because cases are not officially reported until the criteria for AIDS are defined, it is only possible to construct survival estimates from this point, which is a limitation in the interpretation of data. Children diagnosed with HIV infection but without AIDS diagnosis were not included in the study. Thus, the degree of improvement and current levels of survival achieved are difficult to compare with international data from elsewhere. Most publications that examine the survival time of AIDS cases infected through vertical transmission are based on cohorts of HIV-infected children identified at birth or soon after. The survival time is usually calculated from birth or date of HIV infection rather than the date of AIDS diagnosis as evaluated in this study.

Differences in survival by region should also be taken into account when comparing survival results by regions of the country. Compared to the first national study, any such difference probably was less important considering that since 1999 various initiatives were undertaken nationally in Brazil including HIV testing for the general population, improvement of prenatal screening, and follow-up of pregnant women and HIV exposed children.

Problems with the quality and access to medical records of cases in terms of file organization were observed in some services. This includes limitations of available data for epidemiological factors (issues relating to mother and family in general, diagnosis knowledge by the child, caregiver, and others) and clinical factors (record of important dates related to clinical events or the therapies adopted, transfers, current situation of children, among others).

Another factor apparent in a nationwide study of this magnitude is the difficulty in following the evolution of individual cases. This is due to changes in the site of medical care of children after reporting (different from the listed site in the SINAN data base), and poorly or undocumented clinic attendance.

The scenario for the future efforts to address AIDS in children presents a number of challenges related not only to the pathogenesis of HIV infection in this population 31 , but also in relation to the management of children exposed to HIV over these years 32,33,34. Analysis of the Brazilian experience shows that in a country with limited resources, and large geographical and social inequalities, it is possible to establish a system capable of providing free and universal access to HAART and diagnosis of HIV infection 17,35. Many low and middle income countries still have similar survival results to Brazil in the preHAART era, despite the advances achieved 24,36. The Brazilian findings demonstrate the practical possibilities of dealing with this problem in these countries.

Despite clear advances, as the results show, there is a need to enhance the implementation of technical and organizational recommendations for the Brazilian National STD/AIDS Program. The challenge is to extend improvements not only in the quantity but also the quality of health care 14. This reinforces the need for future population-based and in-depth studies incorporating data that reflect the performance of different areas of the country. Survival studies are essential for the evaluation of intervention strategies aimed at prolonging the life of these patients, and can help inform the needs for clinical care and the establishment of public policies 15 .

The Unified National Health System faces new challenges. One is the presence of adoles- 
cents and adults infected through their mothers, which increases the need for a longitudinal and a holistic approach involving not only biological, but also psychological and social aspects.

In conclusion, the results of the second national study point to the successes of Brazilian policies in addressing AIDS among children, with a significant and sustained increase in the sur- vival probability over several years, due in large part to the use of HAART. The improvement in clinical status is a reflection of these results and is probably accompanied by a similar improvement in quality of life of these children. These data demonstrate the feasibility of incorporating these strategies, even in a country with great social inequalities.

\section{Resumo}

Este estudo caracteriza a sobrevida em crianças com AIDS no Brasil entre 1999-2002, contextualizando com o primeiro estudo nacional (1983-1998). Trata-se de coorte histórica, com crianças expostas ao HIV por transmissão vertical e acompanhadas até 2007. A probabilidade de sobrevivência em 60 meses foi analisada segundo sexo, ano de nascimento e de óbito, classificação clínica, uso de terapia antirretroviral (TARV) $e$ de profilaxia para doenças oportunistas. No total, 920 crianças foram incluídas. A probabilidade de sobrevivência foi ampliada 3,5 vezes nos dois períodos avaliados, passando de 25\% antes de 1988 para 86,3\% no período de 2001-2002. Uso de TARV, classificação clíni- ca inicial e atual/final foram preditores que influiram significativamente $(p<0,001)$ para a ampliação da sobrevida. Os resultados deste estudo indicam o sucesso da política brasileira para a abordagem das crianças infectadas com HIV. A melhora do estado clínico contribuiu para melhora da qualidade de vida, mas sinaliza-se para a necessidade de incorporação de práticas pautadas na integralidade do cuidado.

Síndrome de Imunodeficiência Adquirida; Transmissão Vertical de Doença Infecciosa; Análise de Sobrevida; Terapia Anti-Retroviral de Alta Atividade 


\section{Contributors}

L. H. Matida was the coordinator, responsible for: design of the study, collection, consolidation and analysis of data and for writing the article in its final version. A. $\mathrm{N}$. Ramos Jr. was the assistant coordinator, participating in designing the project, the collection, consolidation, analysis and interpretation of data, as well as for writing the article in its final version. J. Heukelbach participated in the analysis and interpretation of data and writing the article in its final version. A. Sañudo participated in the analysis and interpretation of data and writing the article in its final version. R. C. M. Succi, H. H. S. Marques and M. D. Negra participated in the discussion of the design of the study, collection and writing the paper in its final version. N. Hearst participated in the design of the study, analysis and interpretation of data and writing the article in its final version.

\section{Acknowledgements}

The authors wish to thank the health services who participated in and the people who contributed to this study. Mariângela Simão, Pedro Chequer, Maria Clara Gianna, Maria Goretti Medeiros, Gerson Pereira, Francisca Lucena and Artur Sousa supported and facilitated the overall process. Adriana Sañudo and Maria Cecília Goi Porto Alves provided statistical support. The Brazilian Study Group on Survival of Children with AIDS - Second Study - data collection team included: Adelia A. Bispo, Adriana V. A. Ramos, Alberto E. O. M. Silva, Alexandre Gonçalves, Ana S. P. Gibbons, Aparecida H. U. Facuri, Arlete C. M. Dias, Aroldo P. Carvalho, Bianca R. Lucarevschi, Carlos A. Correa, Carmem L. O. Silva, Dalel Haddad, Denise A. Rocha, Eduardo Caminada Jr., Elizabete P. Yamaguti, Fatima Sumaya, Jorge Pinto, Joria V. Guerreiro, Katharine S. Freitas, Leidiane V. Silva, Lilian M. Lauria, Maly Albuquerque, Maria C. Cervi, Marcia M. F. J. D. Fabbro, Maria I. S. Heyr, Maria C. S. Barbosa, Maria de Jesus F. Alencar, Maria do Carmo Ferreira, Maria Helena S. Teixeira, Marion Burger, Mylva Fonsi, Neuza Uchiyama, Olinda K. Mizuta, Rosangela M. Coelho, Roseane E. Martello, Sandra F. M. Silva, Simone G. Bernardes, Sirlene Caminada, Sueny S. Martins, Teresa M. I. Nishimoto and Wedja Sparinger. This work was carried out by the Fundação São Vicente (Fundasv) with technical and financial support of the Department of STD, AIDS and Viral Hepatitis, Secretariat of Health Surveillance, Brazilian Ministry of Health through the Project of International Technical Cooperation AD/BRA/03/H34 between the Brazilian Government and the United Nations Office on Drugs and Crime (UNODC).

\section{References}

1. Gibb DM, Duong T, Tookey PA, Sharland M, TudorWilliams G, Novelli V, et al. Decline in mortality, AIDS, and hospital admissions in perinatally HIV-1 infected children in the United Kingdom and Ireland. BMJ 2003; 327:1019.

2. de Martino M, Tovo PA, Balducci M, Galli L, Gabiano C, Rezza G, et al. Reduction in mortality with availability of antiretroviral therapy for children with perinatal HIV-1 infection. Italian Register for HIV Infection in Children and the Italian National AIDS Registry. JAMA 2000; 284:190-7.

3. Patel K, Hernan MA, Williams PL, Seeger JD, McIntosh K, Van Dyke RB, et al. Long-term effectiveness of highly active antiretroviral therapy on the survival of children and adolescents with HIV infection: a 10-year follow-up study. Clin Infect Dis 2008; 46:507-15.

4. Gortmaker SL, Hughes M, Cervia J, Brady M, Johnson GM, Seage GR 3rd, et al. Effect of combination therapy including protease inhibitors on mortality among children and adolescents infected with HIV-1. N Engl J Med 2001; 345:1522-8.
5. Janssens B, Raleigh B, Soeung S, Akao K, Te V, Gupta J, et al. Effectiveness of highly active antiretroviral therapy in HIV-positive children: evaluation at 12 months in a routine program in Cambodia. Pediatrics 2007; 120:e1134-40.

6. Viani RM, Araneta MR, Deville JG, Spector SA. Decrease in hospitalization and mortality rates among children with perinatally acquired HIV type 1 infection receiving highly active antiretroviral therapy. Clin Infect Dis 2004; 39:725-31.

7. Goetghebuer T, Haelterman E, Le Chenadec J, Dollfus C, Gibb D, Judd A, et al. Effect of early antiretroviral therapy on the risk of AIDS/death in HIV-infected infants. AIDS 2009; 23:597-604.

8. Chiappini E, Galli L, Tovo PA, Gabiano C, Lisi C, Gattinara GC, et al. Changing patterns of clinical events in perinatally HIV-1-infected children during the era of HAART. AIDS 2007; 21:1607-15.

9. Gavin PJ, Yogev, R. The role of protease inhibitor therapy in children with HIV infection. Paediatr Drugs 2002:581-607. 
10. Hacker MA, Kaida A, Hogg RS, Bastos FI. The first ten years: achievements and challenges of the Brazilian program of universal access to HIV/AIDS comprehensive management and care, 1996-2006. Cad Saúde Pública 2007; 23 Suppl 3:S345-59.

11. Okie S. Fighting HIV-lessons from Brazil. N Engl J Med 2006; 354:1977-81.

12. Bastos FI, Caceres C, Galvao J, Veras MA, Castilho EA. AIDS in Latin America: assessing the current status of the epidemic and the ongoing response. Int J Epidemiol 2008; 37:729-37.

13. Jeena PM, McNally LM, Stobie M, Coovadia HM, Adhikari MA, Petros AJ. Challenges in the provision of ICU services to HIV infected children in resource poor settings: a South African case study. J Med Ethics 2005; 31:226-30.

14. Matida LH, Ramos Jr. AN, Moncau JE, Marcopito LF, Sousa-Marques HH, Succi RC, et al. AIDS by mother-to-child transmission: survival analysis of cases followed from 1983 to 2002 in different regions of Brazil. Cad Saúde Pública 2007; 23 Suppl 3:S435-44.

15. Matida LH, Marcopito LF, Succi RC, Marques HH, Della-Negra M, Grangeiro A, et al. Improving survival among Brazilian children with perinatallyacquired AIDS. Braz J Infect Dis 2004; 8:419-23.

16. Matida LH, Ramos Jr. AN, Heukelbach J, Hearst N. Continuing improvement in survival for children with Acquired Immunodeficiency Syndrome in Brazil. Pediatr Infect Dis J 2009; 28:920-2.

17. Camargo Jr. KR, Coeli CM. Reclink: aplicativo para o relacionamento de bases de dados, implementando o método probabilistic record linkage. Cad Saúde Pública 2000; 16:439-47.

18. Ministério da Saúde. Boletim Epidemiológico AIDST 2008; Ano V, no. 1.

19. Kaplan EL, Meier P. Non parametric estimation from incomplete observation. J Am Stat Assoc 1958; 53:457-81.

20. Kleinbaum DG, Klein M. Survival analysis - a selflearning text. 2nd Ed. New York: Springer; 2005.

21. Ministério da Saúde. Critérios de definição de casos de AIDS em adultos e crianças. http://www.aids. gov.br/data/documents/storedDocuments /\%7BB8EF5DAF-23AE-4891-AD36-1903553A3174\%7D/\%7B2A9F7D1C-093E-4A04-838084ED432964A5\%7D/criterios.pdf (accessed on 13/ Nov/2009).

22. Cox DR, Oakes D. Analysis of survival data. London: Chapman \& Hall; 1984

23. Marazzi MC, Nielsen-Saines K, Buonomo E, Scarcella P, Germano P, Majid NA, et al. Increased infant human immunodeficiency virus-type one free survival at one year of age in sub-Saharan Africa with maternal use of highly active antiretroviral therapy during breast-feeding. Pediatr Infect Dis J 2009; 28:483-7.
24. Sutcliffe CG, Scott S, Mugala N, Ndhlovu Z, Monze M, Quinn TC, et al. Survival from 9 months of age among HIV-infected and uninfected Zambian children prior to the availability of antiretroviral therapy. Clin Infect Dis 2008; 47:837-44.

25. Little K, Thorne C, Luo C, Bunders M, Ngongo N, McDermott P, et al. Disease progression in children with vertically-acquired HIV infection in subSaharan Africa: reviewing the need for HIV treatment. Curr HIV Res 2007; 5:139-53.

26. Sousa-Marques HH, Couttolenc BF, Latorre MRDO, Aquino MZG, Aveiro MI, Pluciennik AMA. Costs of care provided in a university hospital for children exposed to or infected with the HIV/AIDS. Cad Saúde Pública 2007; 23 Suppl 3:S402-13.

27. Barbosa Junior A, Szwarcwald CL, Pascom ARP, Souza Junior PB. Tendências da epidemia de AIDS entre subgrupos sob maior risco no Brasil, 19802004. Cad Saúde Pública 2009; 25:727-37.

28. Ramos Jr. AN, Matida LH, Saraceni V, Veras MA, Pontes RJ. Control of mother-to-child transmission of infectious diseases in Brazil: progress in HIV/AIDS and failure in congenital syphilis. Cad Saúde Pública 2007; 23 Suppl 3:S370-8.

29. Szwarcwald CL, Barbosa Junior A, Souza Junior PR, Lemos KR, Frias PG, Luhm KR, et al. HIV testing during pregnancy: use of secondary data to estimate 2006 test coverage and prevalence in Brazil. Braz J Infect Dis 2008; 12;167-72.

30. Succi RCM; Grupo de Estudo da Sociedade Brasileira de Pediatria para Avaliar a Transmissão Materno-Infantil do HIV. Mother-to-child transmission of HIV in Brazil during the years 2000 and 2001: results of a multi-centric study. Cad Saúde Pública 2007; 23 Suppl 3:S379-89.

31. Levy JA. HIV pathogenesis: 25 years of progress and persistent challenges. AIDS 2009; 23:147-60.

32. Paintsil E, Andiman WA. Update on successes and challenges regarding mother-to-child transmission of HIV. Curr Opin Pediatr 2009; 21:94-101.

33. King E, De Silva M, Stein A, Patel V. Interventions for improving the psychosocial well-being of children affected by HIV and AIDS. Cochrane Database Syst Rev 2009; (2):CD006733.

34. Little KE, Bland RM, Newell ML. Vertically acquired paediatric HIV infection: the challenges of providing comprehensive packages of care in resource-limited settings. Trop Med Int Health 2008; 13:1098-110.

35. Galvao J. Brazil and access to HIV/AIDS drugs: a question of human rights and public health. Am J Public Health 2005; 95:1110-6.

36. Masanja H, Savigny D, Smithson P, Schellenberg J, John T, Mbuya C, et al. Child survival gains in Tanzania: analysis of data from demographic and health surveys. Lancet 2008; 371:1276-83.

Submitted on 01/Dec/2009

Final version resubmitted on 20/Apr/2010

Approved on 05/Jul/2010 